DOI: $10.1515 /$ pts-2017-0011

PHYSICS

\title{
NANOINDENTATION RESPONSE ANALYSIS OF THIN FILM SUBSTRATES-II: STRAIN HARDENING-SOFTENING OSCILLATIONS IN SUBSURFACE LAYER
}

\author{
Uldis Kanders $^{1}$, Karlis Kanders ${ }^{2}$ \\ ${ }^{1}$ Institute of Mechanical Engineering, \\ Riga Technical University, \\ 6 Ezermalas Str., LV-1006, Riga, LATVIA \\ e-mail: uldis.kanders@gmail.com \\ ${ }^{2}$ Institute of Neuroinformatics, University \& ETH of Zurich \\ 190 Winterthurerstr., CH-8057 Zurich, SWITZERLAND \\ e-mail: kkanders@ini.phys.ethz.ch
}

\begin{abstract}
We have extracted stress-strain field (SSF) gradient and divergence representations from nanoindentation data sets of bulk solids often used as thin film substrates: bearing and tooling steels, silicon, glasses, and fused silica. Oscillations of the stress-strain field gradient and divergence induced in the subsurface layer by the nanoindentation have been revealed. The oscillations are especially prominent in single indentation tests at shallow penetration depths, $h<100 \mathrm{~nm}$, whereas they are concealed in the averaged datasets of 10 and more single tests. The amplitude of the SSF divergence oscillations decays as a sublinear power-law when the indenter approaches deeper atomic layers, with an exponent -0.9 for the steel and -0.8 for the fused silica. The oscillations are interpreted as alternating strain hardening-softening plastic deformation cycles induced in the subsurface layer under the indenter load.
\end{abstract}

Keywords: elastic-plastic deformation, heterogeneity, nanoindentation, strain gradient plasticity, stress-strain field, subsurface layer.

\section{INTRODUCTION}

When bulk solids are used as substrates for deposition of thin and very thin films, a detailed understanding of the substrate surface and subsurface layers at depths of several hundred to thousand nanometers is a prerequisite for an adequate assessment of the deposited thin film mechanical properties. Nanoindentation is a convenient and versatile experimental technique used to characterise the mechanical properties of small volume samples, including subsurface layers of bulk solids, as well as thin films and coatings, or even biological materials like bone, tooth enamel and viruses [1]-[5]. The subsurface layer of bulk solids, especially of polished steel substrates, is, however, usually somewhat deformed and highly heterogeneous and 
may not yield a steady state value of the apparent hardness and/or elastic modulus [3], [6] that would correspond to the so-called material bulk property. In this case, it would be valuable to probe the local gradients and inhomogeneities in a better detail to reveal more information about the microstructure of the sample subsurface layer.

In the first part of this investigation, we derived a simple approach to extract the local stress-strain field (SSF) gradient and divergence representations from the nanoindentation experiment dataset [7]. These representations, in principle, allow discovering weak structural heterogeneities which might point to, for example, interfaces between mechanically distinct local microzones within the subsurface region or work hardening and softening deformation processes induced underneath the indenter. Here, we applied the strain gradient-divergence approach [7] in the analysis of nanoindentation response of bulk solids commonly used as substrates for thin film deposition: different types of bearing and tooling steels, glass, silicon as well as silica as a reference sample without a pretreated surface. A highly dynamic process occurring in the subsurface layer of the bulk solids was revealed during a nanoindentation experiment: oscillations of the stress-strain field gradient and divergence. The gradient-divergence oscillations are best discernible in the single measurement data at shallow penetration depths below $100 \mathrm{~nm}$, where the averaged measurement has the highest variability and thus is commonly discarded. We associate these oscillations with alternating cycles of strain hardening and strain softening processes of the elastic-plastic deformation induced during the indentation experiment. The terms strain hardening and strain softening are used here in a general sense, encompassing many possible underlying specific plastic deformation mechanisms such as slipping, twinning, serration, [8]-[10] etc. (as opposed to the restricted, historical meaning of the terms as processes caused by the dislocation creation and movement in crystalline materials).

\section{METHODS}

\subsection{Experimental Details}

Various bulk samples of steel, glass, silicon, and fused silica substrates were tested in the nanoindentation experiments. The steel samples, labelled as $100 \mathrm{Cr} 6$ (OTAI Special Steel) and SCH (Schaeffler Technologies AG) were classified as bearing steel. The other category of steel samples labelled as CZS and HVG (ProfProkat) corresponded more to tooling steels. All of them were of high quality chrome low-alloy steels closely matching the AISI 52100 steel with minor modifications depending on their respective manufacturers. The glass sample was the hard glass microscope slide VB5 656. In turn, silicon substrates were Si(100) as thick as 0.5 $\mathrm{mm}$ cut off from high quality silicon wafer having root mean square (RMS) less 1 nm. Fused silica was the Corning HPFS 7980, Standard Grade high purity synthetic amorphous silicon dioxide.

Surface morphology, microstructure, phase structure and elemental composition of the samples were estimated by scanning electron microscope (model Hitachi S-4800) equipped with the energy dispersive spectrometer B-Quantax and X-ray fluorescence spectrometer S4 PIONEER. X-ray diffraction structure measurements were performed by Bruker D8 Advance. 
Surface roughness RMS was measured by atomic force microscope (AFM, model Veeco CP-II and Asylum Research, model MFP-3D) in tapping mode. The surface micrographs and phase images were taken from surface area of $20 \mu \mathrm{m} \times 20$ $\mu \mathrm{m}$. Surface profiler Dektak 150 was used to probe surface texture and roughness over a wider area, on the order of millimeter. The Dektak 150 resolution features enabled precise planarity scans for measuring radius of curvature, flatness, and waviness.

Instrumented depth sensing nanoindentation experiments were performed by G200 Nano Indenter (Agilent, USA) with a sharp Berkovich diamond indenter (tip radius $<20 \mathrm{~nm}$ ). Measurements were made in the continuous stiffness measurement (CSM) mode [11] and in the BASIC mode at different values of the maximum load. The load capability of the Nano Indenter G200 reaches up to $600 \mathrm{mN}$ within the standard option. The hardness and elastic modulus of the samples were calculated using Oliver-Pharr method [12] by MTS TestWorks 4 software.

\subsection{Stress-Strain Field Gradient and Divergence Representations}

The specialized elastic-plastic strain gradients are extracted from the experimental load, $P(h)$, stiffness, $S(h)$, elastic modulus, $E(h)$, and hardness, $H(h)$, datasets by

$$
\begin{aligned}
P^{\prime}(h) & \equiv \frac{h}{P(h)} \frac{d P(h)}{d h}-2, \\
S^{\prime}(h) & \equiv \frac{h}{S(h)} \frac{d S(h)}{d h}-1, \\
E^{\prime}(h) & \equiv \frac{h}{E(h)} \frac{d E(h)}{d h}, \\
H^{\prime}(h) & \equiv \frac{h}{H(h)} \frac{d H(h)}{d h},
\end{aligned}
$$

where $P^{\prime}(h)$ represents total strain gradient, $S^{\prime}(h)$ represents elastic total strain gradient, $E^{\prime}(h)$ represents elastic normal strain gradient, and $H^{\prime}(h)$ represents plastic total strain gradient induced beneath the indenter; $h$ is the penetration depth. We will further refer to these functions as the corresponding strain gradients instead of strain gradient representations because they differ by a constant factor only. The specialized total, $P^{\prime \prime}(h)$, elastic total, $S^{\prime \prime}(h)$, elastic normal, $E^{\prime \prime}(h)$, and plastic total, $H^{\prime \prime}(h)$ divergences are given by

$$
\begin{aligned}
& P^{\prime \prime}(h) \equiv \nabla P^{\prime}(h), \\
& S^{\prime \prime}(h) \equiv \nabla S^{\prime}(h), \\
& E^{\prime \prime}(h) \equiv \nabla E^{\prime}(h), \\
& H^{\prime \prime}(h) \equiv \nabla H^{\prime}(h) .
\end{aligned}
$$

For further details on the derivation and discussion of Eqs. 1-2 and on the practical calculation of the stress-strain field gradient and divergence representations cf. Ref. 7. 


\section{RESULTS AND DISCUSSION}

SSF gradient and divergence oscillations induced by nanoindentation were observed in all the examined steel, silicon, glass and silica samples and they manifested similar strain hardening-softening cycles when the sharp Berkovich indenter penetrated the subsurface layer. Results on the bulk solid sample of silicon were reported in the first part of this investigation [7]. For the clarity of the discussion we focus here on reporting a few typical results of the nanoindentation measurements of the CZS sample, which are representative of all the steel samples examined in our investigation. In addition, results from the well-known and widely used reference material fused silica are also displayed to showcase the generality of the SSF gradient-divergence oscillation phenomenon. We also provide a preliminary quantitative analysis of the oscillations.

\subsection{SSF Gradient and Divergence Oscillations}
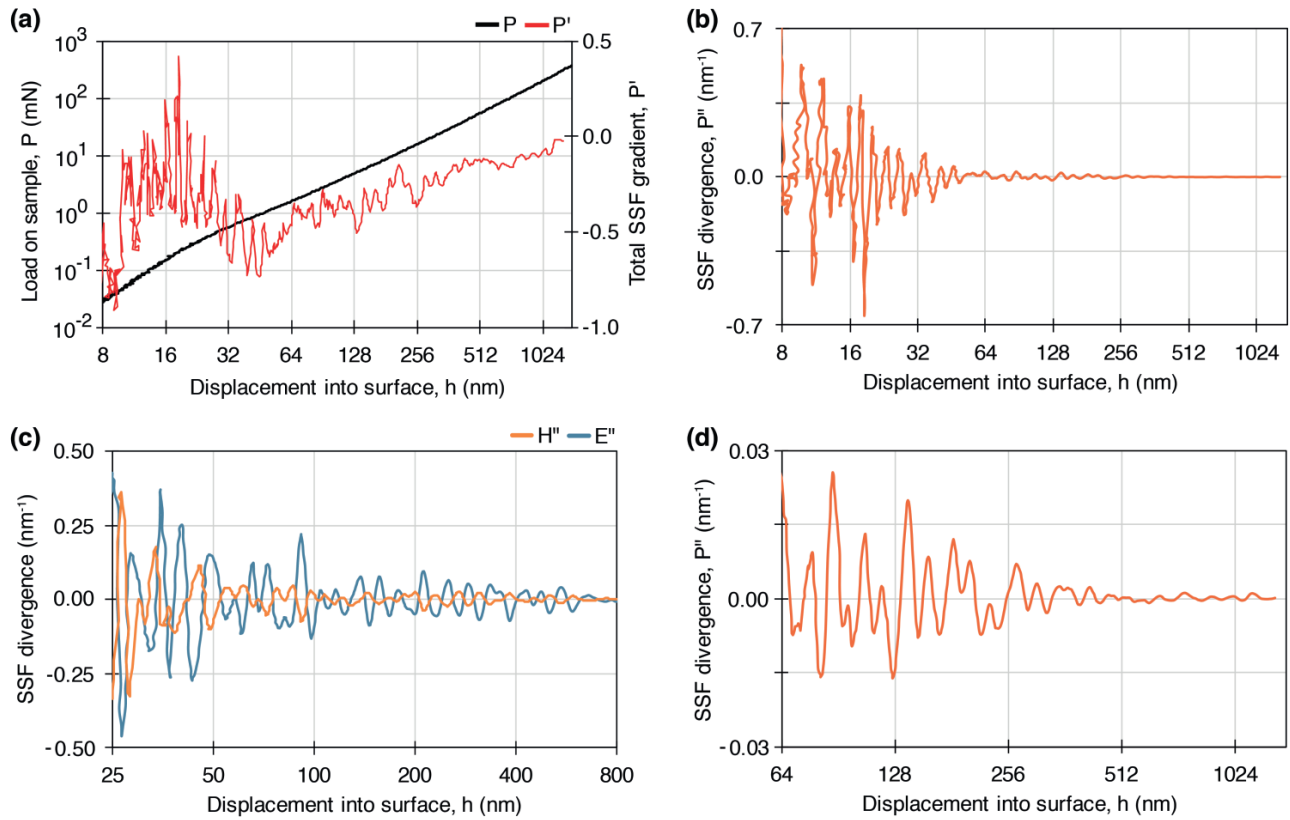

Fig. 1. Total stress-strain field gradient and divergence oscillations in the CZS sample:

(a) A typical example of the load-displacement, $P$ - $h$, curve (black) and the total SSF gradient, $P^{\prime}-h$, curve (gray) obtained from a single indentation test in the CSM mode;

(b) Total SSF divergence oscillations obtained from the same measurement;

(c) Plastic normal ( $H$ "'- $h$ curve, gray) and elastic normal ( $E$ "'- $h$ curve, black ) SSF divergence oscillations calculated from the same measurement; (d) Close-up of the total SSF divergence low amplitude oscillations from (b) at larger penetration depths. 
Figure 1(a) shows a typical example of a single nanoindentation test measurement (as opposed to an averaged measurement) in the CSM mode of the CZS steel sample. The load-displacement curve is contrasted with the corresponding total SSF gradient curve, which was derived using the approach briefly outlined in Methods (see also Ref. 7). Note that we use logarithmic axis for the displacement into surface, $h$, to highlight nanoindentation responses at the subsurface layers. Clear oscillations of the SSF gradient can be observed already starting from $8 \mathrm{~nm}$ depth despite the measurement noise. The total SSF divergence oscillations are shown in Fig. 1(b). Very similar oscillations were observed for all 19 single nanoindentation tests of the CZS steel sample. The SSF gradient-divergence oscillations were observed throughout the indentation measurement, even at large indenter penetration depths (see Fig. 1(d), where the SSF divergence oscillations are present at up to more than $1000 \mathrm{~nm}$ ). Therefore, they cannot be solely attributed to the structural inhomogeneities related to surface roughness, which based on the RMS measurements was only $2-3 \mathrm{~nm}$, or the superficial layer.

The oscillations of the strain gradient might be caused by alternating normal-shear strain transformation processes converting strains into each other: as the sharp Berkovich indenter penetrates the sample the normal strain builds up until the sample structure cannot withstand it anymore and some sliding of elastically deformed region occurs, i.e., shear strain leads to plastic deformation. Furthermore, the incremental stresses induced by indenter interact with the structural stresses inherent in the subsurface layer. The amplitude of the SSF gradient-divergence oscillations is larger closer to the surface, where free- and near-surface layer acts as a large structural defect in comparison with the atomic structure in bulk. Subsequently, the amplitude decayed rather rapidly as the indenter penetrated deeper into the sample and approached its bulk structure that was far enough from the free surface.

Figure 1(c) shows the total plastic SSF divergence, $H$ "'- $h$ curve, and the elastic normal SSF divergence, $E$ "' $h$ curve, that were derived from the hardness and elastic modulus indentation datasets, respectively. Divergences $H^{\prime \prime}(h)$ and $E^{\prime \prime}(h)$ tells us at which $h$ values the interface between the hydrostatic core and the plastic deformation zone acts as a stress-strain flux source or sink. Therefore, depth intervals where the divergence of the corresponding component of the SSF is positive can be interpreted as strain hardening of the sample subsurface layer. Within these depth intervals, the subsurface layer acts as a SSF flux source. Similarly, the penetration depth intervals of negative divergence can be interpreted as strain softening of the subsurface layer. In turn, the plastic deformation zone underneath the indenter acts as a stress-strain flux sink. The oscillations in Fig. 1(c) reveal a structure of strain hardening-softening zones induced by the sharp Berkovich indenter. The oscillations of the elastic and plastic SSF divergences were out of phase, which indicated that elastic and plastic deformation processes in the subsurface layer happened in an alternating fashion. This is in a good agreement with the physical nature of the elastic-plastic deformation where plastic deformation processes follow the elastic ones regardless of the specific mechanism. The sample in the subsurface layer is expected to be rather heterogeneous having different sized nanograins, nanoparticles, dislocations within nanocrystallites, nanovoids, etc. This gives rise to many different specific plastic deformation mechanisms that might occur underneath the loaded indenter during the nanoindentation experiment: slipping, twinning, cold working, grain boundary 
sliding, strain bursts or flow serrations, shear band formation, stick and slip events, among others [8]-[10], [13], [14].For example, nanovoids can be frequently present, which then can be packed by the applied load during the indentation process. The process of packing is largely a plastic deformation causing a strain hardening effect, which is indicated by the positive divergence of the plastic SSF divergence $(H$ " $(h)>0)$. However, any discrete plastic deformation event has its own early elastic phase manifested here by the overtaking positive elastic SSF divergence $\left(E^{\prime \prime}(h)\right.$ $>0$ ). Elastic phase can happen only up to the point where the elastic limit has not exceeded yet. After the local yield point is reached, the elastic strain triggers the corresponding plastic one. Yielding and hardening effects lead to further development of plastic strain under load. However, progressing plastic strain thereafter discharges the preceding elastic stresses as it is shown by the out-of-phase oscillations of $E$ "- $h$ and $H$ "'- $h$ curves in Fig. 1(c). In turn, strain-softening effect may occur after grain boundary sliding when some portion of the substance is pushed out of the plastic zone underneath the indenter and internal elastic pressure thereafter drops down. Of course, the grain boundary sliding event has its own early elastic phase as well.

\subsection{SSF Gradient and Divergence from Averaged Datasets}

The SSF gradient calculated from the averaged load-displacement curves of the CZS sample was much smoother than in the single measurements and the oscillations were practically not visible (Fig. 2). SSF divergence oscillations could still be detected albeit they were markedly smaller in amplitude compared to the single tests (Fig. 3). The strain hardening-softening zones (HSZ) in Fig. 3 are highlighted by applying the sign function on the corresponding components of SSF divergence (e.g., $\left.\operatorname{HSZ}\left(E^{\prime \prime}\right)=\operatorname{sign}\left(E^{\prime \prime}\right)\right)$, revealing similar pattern seen in the case of single measurements: the strain hardening $(\mathrm{HSZ}>0)$ and softening $(\mathrm{HSZ}<0)$ cycles of the elastic and plastic components of SSF divergence tend to happen in an alternating fashion. However, generally the attempts to detect strain gradient-divergence oscillations from the averaged dataset will be impaired because the oscillations of the single indentation tests are shifted in phase with respect to each other and averaging will to a large extent smoothen them out. However, less subtle fluctuations, e.g., due to a layered atomic microstructure in the case of thin films may still be detectable with the strain gradient-divergence approach also in the averaged indentation dataset [15]. For example, the averaged SSF gradient curve for the CZS steel had a pronounced convex shape (see Fig. 2), which is in a good agreement with the model where the subsurface layer plays role of the skin of bulk materials and it has to endure a very large pressure difference between the outside and inside of the bulk sample (i.e., the skin effect). This is easy to understand as the pressure at the free surface of the sample is about $0.1 \mathrm{MPa}$, whereas the pressure inside the bulk samples reaches values of about $1000 \mathrm{MPa}$ and higher. The pressure between the outside and inside of the sample differs on the order of $10^{4}-10^{5}$ times, which makes the atomic layers within the subsurface area very stressed in comparison with those lying deeper inside the sample, far away from the free surface. The stresses within the subsurface layer are lowering when indenter is loading the surface of the bulk sample, which can be interpreted as strain softening of the subsurface layer at the beginning phase of the nanoindentation measurement. 


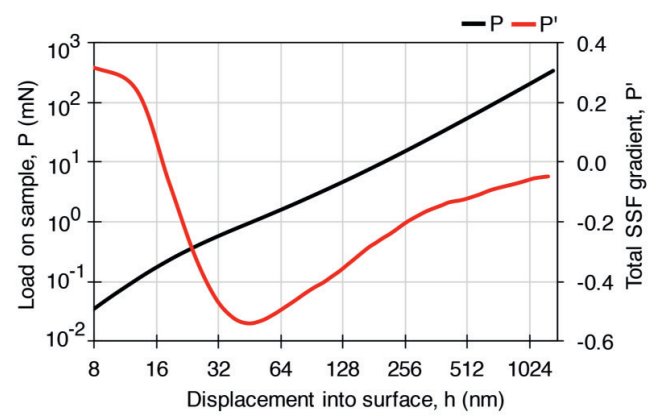

Fig. 2. The strain gradient oscillations of the CZS steel sample are smoothened out when the total strain gradient-displacement, $P^{\prime}-h$, curve (gray) is calculated from the averaged $(n=19)$ load-displacement, $P$ - $h$ (black).
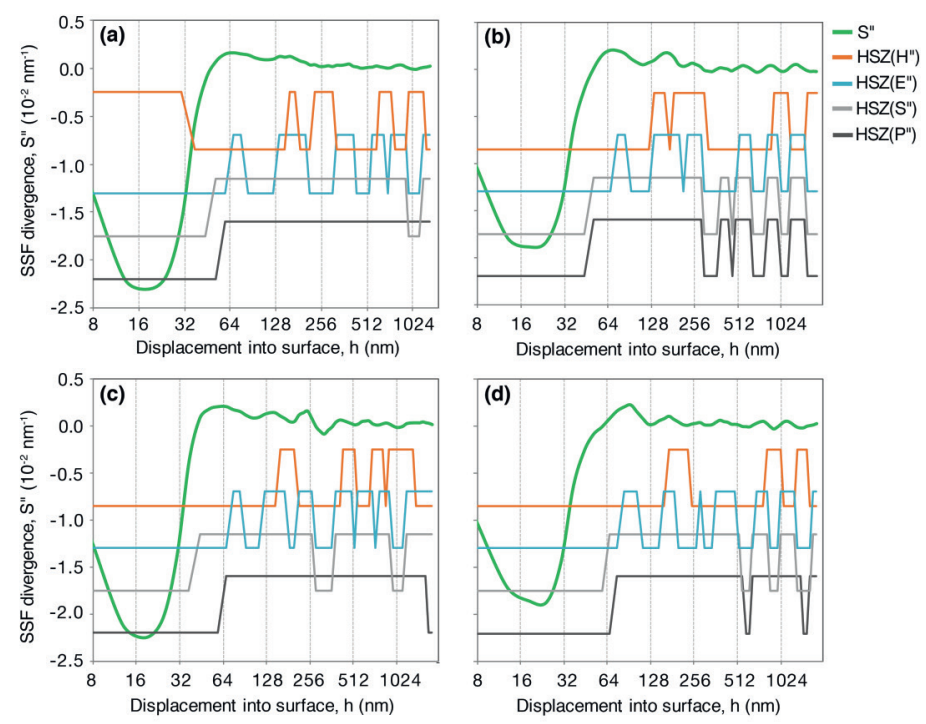

Fig. 3. SSF divergence oscillations are also present, albeit much less prominently, in the averaged nanoindentation datasets of the steel samples: (a) CZS, (b) 100Cr6, (c) SCH, (d) HGV. Total elastic SSF divergence, $S$ "- $h$, curve, is shown together with the strain hardening-softening zones (HSZ) of the corresponding SSF divergence components; the HSZ curves are vertically offset for presentation purposes.

\subsection{Additional Tests for the Presence of Strain Gradient Oscillations}

In the CSM mode, weak superimposed oscillations are applied additionally to the load-time frame in order to measure the apparent hardness and elastic modulus throughout the loading process. This might in principle introduce some fluctuations of the sample mechanical properties and potentially even alter the indentation measurement results [16]. The CSM mode oscillations happen on a much faster timescale than the strain gradient-divergence oscillations and thus it was highly unlikely that CMS mode could affect the results. However, to confirm that the stress-strain gradient oscillations are not an artefact of the CSM loading mode, additional nanoindentation tests were made in the so-called BASIC mode, where the applied load was increasing up to the maximum load without any superimposed shallow oscillations 
during the loading process. Figure 4(a) shows that the stress-strain field gradient exhibits clear oscillations also when the indentation experiment is carried out in the BASIC mode.

Subsurface layer mechanics of steel samples may differ from that of glass samples because the surface of steel samples needs grinding and polishing before it is possible to carry out nanoindentation experiments. In turn, grinding and polishing of the steel sample may result in, e.g., Beilby layer having somewhat specific structure and mechanics [17], [18]. In contrast, glass samples in most cases do not need a special treatment of the surface after they are manufactured from the glass liquid phase. To test whether the SSF gradient oscillations are not just a peculiarity of the steel material, we indented a sample of a well-known reference material, the fused silica. Prominent stress-strain field gradient oscillations were present in all eight single indentation tests we performed (see Fig. 6(b) for a typical example).
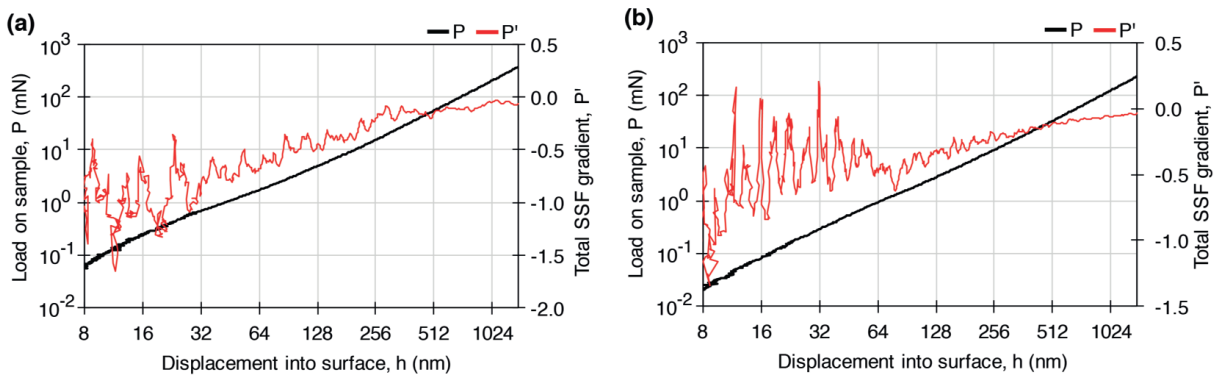

Fig. 4. Additional tests of the strain gradient oscillation phenomenon: the load-displacement, $P$ - $h$, curve (black) and the total SSF gradient, $P$ "- $h$, curve (gray) from a typical single measurement in (a) CZS steel in BASIC mode and (b) fused silica in CSM mode.

\subsection{Quantitative Features of the Oscillations}

Are the stress-strain field gradient-divergence oscillations specific for each material? We compared the decay behavior of the total plastic SSF divergence oscillations of CZS steel and fused silica by finding the positive peaks of $H^{\prime \prime}-h$ curves, $H^{\prime \prime}{ }_{\text {peak }}(h)$, and plotting them against the penetration depth, $h$ (Fig. 5). $H^{\prime \prime}{ }_{\text {peak }}(h)$ was defined as the maximum positive value between two consecutive crossings of the displacement $h$-axis of the $H$ "'- $h$ curve. The amplitude of oscillations for the steel sample was generally lower except at very shallow penetration depths. The amplitude for both materials decayed monotonically with increasing penetration depth. However, there appear to be two different stages of oscillations: an initial stage of gradually decaying, higher amplitude oscillations followed by a rather sharp, discontinuous drop in amplitude at a penetration depth of approximately $h=30 \mathrm{~nm}$ for the CZS sample and $h=60 \mathrm{~nm}$ for the fused silica. After the sharp decrease, the amplitude again continues to decay more gradually. The smaller amplitude oscillations appear to decay to the first approximation as a power-law, i.e., $H^{\prime \prime}{ }_{\text {peak }}(h) \propto h^{\alpha}$, with the exponent $\alpha=-0.9$ and $\alpha=-0.8$ for steel and fused silica, respectively. Interestingly, the half-wave length of the $H^{\prime \prime}(h)$ oscillations, $\lambda_{1 / 2}(h)$, defined as the distance in $h$ between two consecutive crossings of the $h$-axis, increased linearly with increasing penetration depth for both steel and fused silica (Fig. 6). Alternatively, the half-wave 
length can be expressed as a function of the wave number, $N$, in which case $\lambda_{1 / 2}(N)$ grows exponentially.
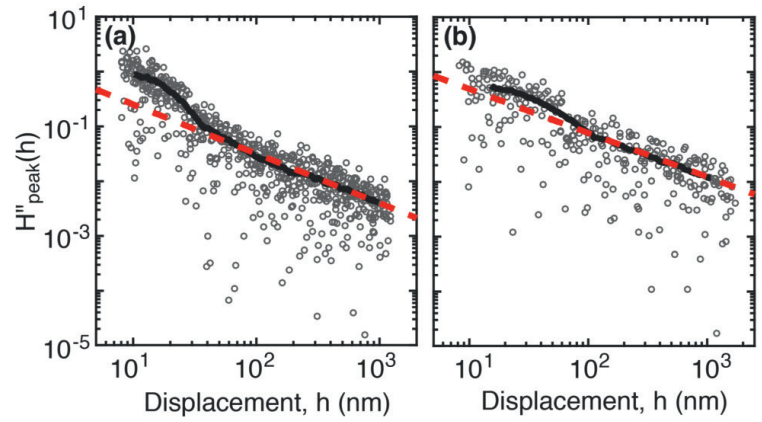

Fig. 5. $H$ "' $(h)$ peak amplitude, $H$ "' $(h)$, as function of the penetration depth, $h$, for (a) steel $(n=19$ tests) and (b) fused silica ( $n=8$ tests). Gray open circles are pooled data from all tests; black, solid lines show a moving average over 60 points of the pooled and sorted dataset to reveal the trend of the $H^{\prime \prime}{ }_{\text {peak }}(h)$ decay; gray, dashed line demonstrates a power-law relationship $H^{\prime}{ }_{\text {peak }}(h) \propto h^{\alpha}$ with the exponent $\alpha=-0.9$ in (a) and $\alpha=-0.8$ in (b).
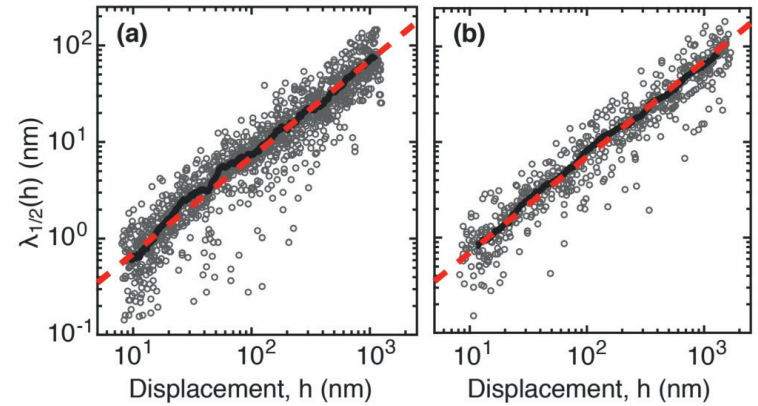

Fig. 6. Half-wave length of the $H^{\prime \prime}(h)$ oscillations, $\lambda_{1 / 2}(h)$, as a function of the penetration depth, $h$, for (a) steel ( $n=19$ tests) and (b) fused silica ( $n=8$ tests). Gray open circles are pooled data from all tests; black, solid line shows a moving average over 60 points of the pooled and sorted dataset to reveal the trend of the $\lambda_{1 / 2}(h)$ growth; gray, dashed line demonstrates a linear relationship $\lambda_{1 / 2}(h) \propto h$ in both (a) and (b).

Overall, the analysis suggests that the SSF divergence oscillations have a quasi-regular, material specific structure with the amplitude and period changing in a regular manner, which follows a well-defined mathematical relationship with respect to the indentation depth. However, further investigations together with more detailed morphological assessment techniques as a reference (e.g., using cross-sectional transmission electron microscopy [19]) are necessary to elucidate oscillation features pertaining to specific mechanical properties of the sample subsurface layer.

\section{CONCLUSIONS}

We have found that nanoindentation experiment with a sharp Berkovich indenter induces SSF gradient-divergence oscillations in the bulk solids. The oscillations are especially prominent at low indentation depths $(<100 \mathrm{~nm})$ indicating that they are primarily a property of the bulk solid subsurface layer. The oscillation 
amplitude decays rapidly as the indenter approaches deeper atomic layers, but some fluctuations can still be detected even at displacements greater than $1000 \mathrm{~nm}$. We have interpreted the oscillations as alternating strain hardening and softening cycles taking place in the subsurface layers under the indenter load. The fading of the oscillations at deeper atomic layers of the sample (i.e., closer to the "in bulk" region) manifests that deformation processes underneath the indenter have reached a steady state where the nanohardness and elastic modulus do not change anymore under continued loading of the sample. Although the elastic and plastic stress-strain fields are superimposed, it was possible to separate their respective components and study elastic and plastic deformation processes selectively. We have observed that elastic and plastic strain hardening and softening cycles happen in an alternating fashion, which agrees with the nature of elastic-plastic deformation.

The strain hardening-softening oscillations have been observed in all the studied samples. Steel has a polycrystalline lattice structure, whereas glass is an amorphous material, and the specific deformation mechanisms in both types of materials can be different. However, these results suggest that the alternating cycles of work hardening and softening effects are a general phenomenon occurring in bulk solids when their surface is loaded by the incremental stress. Preliminary quantitative analysis suggests that the oscillations have features that are typical of different materials, but further investigations, preferably together with detailed morphological characterization of the sample microstructure are necessary to fully discover the potentially valuable information about the mechanical properties of the material subsurface layer hidden in the strain gradient-divergence oscillations.

\section{ACKNOWLEDGEMENTS}

The authors thank Dr. Roberts Zabels at the Institute of Solid State Physics, University of Latvia for providing the datasets of the nanoindentation and AFM experiments, and Prof. Janis Maniks for encouraging and helpful discussions.

\section{REFERENCES}

1. Fischer-Cripps, A. (2004). Nanoindentation. New York: Springer-Verlag.

2. Oyen, M.L., \& Cook, R.F. (2009). A practical guide for analysis of nanoindentation data. J. Mech. Behav. Biomed., 2, 396-407.

3. Guo, Y.B., \& Warren, A.W. (2005). Microscale mechanical behavior of the subsurface by finishing processes. J. Manuf. Sci. Eng., 126, 333-338.

4. Warren, A.W., Guo, Y.B., \& Weaver, M.L. (2006). The influence of machining induced residual stress and phase transformation on the measurement of subsurface mechanical behavior using nanoindentation. Surf. Coat. Tech., 200, 3459-3467.

5. Michel, J.P., Ivanovska, I.L., Gibbons, M.M., Klug, W.S., Knobler, C.M., Wuite, G.J.L., \& Schmid, C.F. (2006). Nanoindentation studies of full and empty viral capsids and the effects of capsid protein mutations on elasticity and strength. Proc. Natl. Acad. Sci. USA, 103, 6184-6189.

6. Sangwal, K. (2000). On the reverse indentation size effect and microhardness measurement of solids. Mater. Chem. Phys., 63, 145-152. 
7. Kanders, U., \& Kanders, K. (2017). Nanoindentation response analysis of thin film substrates-I: Strain gradient-divergence approach. Latv.J. Phys.Tech. Sci., 54(1), 66-76, DOI: 10.15.15/lpts-2017-0007

8. Klaumuenzer, D., Maass, R., \& Loeffler, J.F. (2011). Stick-slip dynamics and recent insights into shear banding. J. Mater. Res., 26, 1453-1463.

9. Schuh, C.A., \& Nieh, T.G. (2003). A nanoindentation study of serrated flow in bulk metallic glasses. Acta Mater., 51, 87-99.

10. Chakraborty, R., Dey, A., \& Mukhopadhyay, A.K. (2010). Loading rate effect on nanohardness of soda-lime-silica glass. Metall. Mater. Trans. A 41, 1301-1312.

11. Hay, J.L., Agee, P., \& Herbert, E.G. (2010). Continuous stiffness measurement during instrumented indentation testing. Exp. Techniques, 34, 86-94.

12. Oliver, W., \& Pharr, G. (2004). Measurement of hardness and elastic modulus by instrumented indentation: advances in understanding and refinements to methodology. $J$. Mater. Res., 19, 3-20.

13. Li, H., Ngan, A.H.W., \& Wang, M.G. (2005). Continuous strain bursts in crystalline and amorphous metals during plastic deformation by nanoindentation. J. Mater. Res., 20, 3072-3081.

14. Maniks, J., Mitin, V., Kanders, U., Kovalenko, V., Nazarovs, P., Baitimirova, M., Meija, R., Zabels, R., Kundzins, K., \& Erts, D. (2015). Deformation behavior and interfacial sliding in carbon/copper nanocomposite films deposited by high power DC magnetron sputtering. Surf. Coat. Tech., 276, 279-285.

15. Kanders, U., Kanders, K., Maniks, J., Mitin, V., Kovalenko, V., Nazarovs, P., \& Erts, D. (2015). Nanoindentation response analysis of Cu-rich carbon-copper composite films deposited by PVD technique. Surf. Coat. Tech., 280, 308-316.

16. Siu, K.W., \& Ngan, A.H.W. The continuous stiffness measurement technique in nanoindentation intrinsically modifies the strength of the sample. Philos. Mag., 93, 449-467.

17. Beilby, G. (1921). Aggregation and Flow of Solids. London: Macmillan.

18. Bhushan, B. (Ed.) (2001). Modern Tribology Handbook. CRC Press.

19. Lloyd, S.J., Castellero, A., Giuliani, F., Long, Y., McLaughlin, K.K., Molina-Aldareguia, J.M., Stelmashenko, N.A., Vandeperre, L.J., \& Clegg, W.J. (2005). Observations of nanoindents via cross-sectional transmission electron microscopy: A survey of deformation mechanisms. Proc. R. Soc. A, 461, 2521-2543.

20. Misra, A., Verdier, M., Lu, Y.C., Kung, H., Mitchell, T.E., Nastasi, M., \& Embury, J.D. (1998). Structure and mechanical properties of $\mathrm{Cu}-\mathrm{X}(\mathrm{X}=\mathrm{Nb}, \mathrm{Cr}, \mathrm{Ni})$ nanolayered composites. Scripta Mater., 39, 555-560.

\section{VAKUUMA PĀRKLĀJUMU SUBSTRĀTU NANOINDENTĒŠANAS DATU ANALİZE-II: UZKALDINĀŠANAS-ATKALDINĀŠANAS OSCILĀCIJAS PIEVIRSMAS SLĀNI}

\section{Kopsavilkums}

Šajā pētījumā analizēti dažādu tēraudu, stikla un kausēta kvarca masīvu paraugu pievirsmas deformācijas procesi. Tā kā minētie materiāli parasti tiek izmantoti kā substrāti plānu vakuuma pārklājumu izgulsnēšanai, tad pētījuma rezultāti ir aktuāli arī plāno kārtiņu fizikas un mikroelektronikas nozarēs. No nanoindentēšanas eksperimenta datiem tika izskaiț̣ots indentēšanas radītais deformācijas gradients un 
diverğence. Deformācijas gradienta un diverǵences oscilācijas norādīja uz dinamiskiem procesiem, kas saistīti ar materiālu lokāliem uzkaldināšanas un atkaldināšanas procesiem pievirsmas slānī. Uzkaldināšanas-atkaldināšanas procesu dinamika sevišķi spilgti bija izteikta pie maziem iespiešanās dzilumiem $(h<100 \mathrm{~nm})$. Augot $h$, to amplitūda pakāpeniski samazinājās, taču tika novērota pat līdz $h=1000 \mathrm{~nm}$ un vēl lielākiem indentora iespiešanās dziļumiem.

22.02.2017. 